\title{
Analgesic effects of gabapentine in tonsillectomy
}

\author{
Waleed Abdelmageed*, Salah Abdelrazik**, Ahmad Nassar** \\ And Mohamed Abdelkawi** \\ *Department of Anesthesia and Intensive Care, \\ **Department of E.N.T. King Abdulaziz Naval Base Hospital, Jubail, KSA.
}

\begin{abstract}
Objectives: To evaluate the preemptive effects of gabapentin on postoperative pain relief and its effect on meperidine consumption in patients undergoing tonsillectomy.

Methods: This study took place in King Abdulaziz Naval Base Hospital in the year 2009. Sixty patients ASA I and II were randomly assigned in a prospective randomized double- blind placebo-control clinical trial. Gabapentine $1200 \mathrm{mg}$ or placebo was given orally two hours before induction of anesthesia to patients undergoing tonsillectomy under general anesthesia. Postoperative pain score was recorded on a visual analogue scale at 1, 3, 6, 12, 18 and 24 postoperative hours. Patients received meperidine $1 \mathrm{mg} / \mathrm{kg}$ i.m once every $4 \mathrm{~h}$ if pain score $\geq 3$ or if requested by the patient. Total dose of meperidine consumption was recorded.

Results: Thirty patients in the gabapentine group and 30 patients in the placebo group completed the study. Patients in gabapentine group had significantly lower pain score in comparison to placebo group. Total postoperative meperidine consumption in the gabapentin group was $(48.8 \pm 33.9$ VS $93.8 \pm 54.6)$ in the placebo group $(\mathrm{P}<0.001)$. There was higher incidence of nausea, vomiting, and use of antiemetic drugs in the placebo group.
\end{abstract}

Conclusion: Preemptive use of gabapentine decreased pain score and post operative meperidine consumption and reduced meperidine -related adverse effects in patients undergoing tonsillectomy under general anesthesia.

\section{Introduction}

Postoperative pain is a major factor that affect recovery from anesthesia and surgery. The treatment of postoperative pain after tonsillectomy presents a challenge. Tonsillectomy is associated with unacceptable intense pain during the first 24 hours after surgery ${ }^{1}$. Consistent delivery of first class postoperative pain control is still a major challenge. Opioids are inevitably associated with emesis and the risk of respiratory depression ${ }^{2}$. Local anesthetic techniques are often short lived and required interventional procedures, and the use of non steroidal antiinflammatory drugs ( NSAIDs) is limited by the well known complications and concerns. A combination of opioid and non opioid analgesic drugs improve the quality of postoperative analgesia and reduce opioid consumption as well as their related side effects ${ }^{3}$.

Gabapentine, an anticonvulsant drug with structural analogue of gamma amino butyric acid which was introduced in the year 1994 particularly for partial seizures ${ }^{4}$. It alleviates pain and prevents acute nociceptive and inflammatory pain both in animals and volunteers, especially when given before trauma ${ }^{5,6}$.

Despite its name, gabapentine does not bind at the GABAa or GABAb receptors, however, it has a high binding affinity for the $\alpha 2 \delta$ subunit of the presynaptic voltage gated calcium channels which inhibit calcium influx and subsequent release of 

excitatory neurotransmitters in the pain pathway (as substance $\mathrm{P}$ and calcitonin gene-related peptide $)^{7}$.

Recently, several reports have indicated that preoperative administration of gabapentine may have a place in the treatment of postoperative pain after different surgical procedures; including, breast surgery ${ }^{3}$, lumber discoidectomy surgery ${ }^{2}$, and thyroid surgery ${ }^{8}$ either given preemptively or post incision ${ }^{9}$. Gabapentine is a well -tolerated and safe drug ${ }^{3,10}$. Studies have shown a synergistic effect of gabapentine; as regard its analgesic action; with morphine in animal experiments and in humans ${ }^{11}$

\section{Material and Methods}

After approval of the Hospital Ethics Committee and informed written consents were obtained from all patients, 60 patients American society of anesthesiologists (ASA) I - II scheduled for tonsillectomy under general anesthesia were enrolled.

Patients were eligible if they were between 18 and 35 years old. Exclusion criteria were body weight exceeding $20 \%$ of ideal body weight, known allergy to gabapentine, chronic pain, daily intake of analgesics or corticosteroids, and impaired liver or kidney functions.

The use of visual analogue score (VAS) using a rule where $0 \mathrm{~cm}=$ no pain and $10 \mathrm{~cm}=$ the worst possible pain was explained to all patients included in this study.

Patients were randomly assigned to receive either $1200 \mathrm{mg}$ oral gabapentine ( neurontin $400 \mathrm{mg}$ capsule; Pfizer, Germany ) [Gabapentine group] or placebo [Placebo group] two hours before surgery.

Premedication was accomplished by midazolam $0.06 \mathrm{mgl} / \mathrm{kg}$ im, $30 \mathrm{~min}$. before surgery. Anesthesia was induced with ( propofol $2 \mathrm{mg} / \mathrm{kg}$ i.v. , atracurium $0.5 \mathrm{mg} / \mathrm{kg}$ i.v. and fentanyl $1 \mathrm{ug} / \mathrm{kg}$ i.v.) . Anesthesia was maintained with sevoflurane $1 \%$ inspired at a fresh gas flow rate of $5 \mathrm{~L} / \mathrm{min}$ in combination with nitrous oxide $60 \%$ in oxygen.

The concentration of agents was adjusted to maintain adequate depth of anesthesia (stable heart rate and blood pressure) within $20 \%$ of the base line values.

Monitoring during anesthesia comprised of continuous electrocardiogram and heart rate, pulse oximetry, non invasive arterial pressure, measurements of end tidal $\mathrm{CO} 2$ and measurements of end tidal agent concentration. All parameters were recorded at five -minutes intervals.

At the end of surgery, residual neuromuscular block was antagonized with atropine $0.02 \mathrm{mg} / \mathrm{kg}$ and neostigmine $0.04 \mathrm{mg} / \mathrm{kg}$ i.v.

After tracheal extubation and awakening from anesthesia patients were transferred to the post anesthesia care unit (PACU).

After surgery, an anesthesiologist who was not part of the anesthesia team recorded the pain score at 1,3,6,12,18,24 hour postoperatively, the maximum pain score at different time intervals for each patients were considered for statistical analysis. Meperidine $1 \mathrm{mg} / \mathrm{kg}$ i.m. every $6 \mathrm{~h}$ was given for postoperative pain relief if pain score $\geq 3$ or if requested by the patient. The worest pain score was recorded at the first dose of meperidine injection. The time of first dose of meperidine injection and the total consumption of meperidine within 24 hours is calculated.

Post operative side-effects related to meperidine, as nausea and vomiting, respiratory depression, dizziness and somnolence were recorded in the (PACU) and in the ward . Nausea was recorded for each patient in a four points scale ( none, light, moderate or severe) .Sedation was also recorded on a sedation score using a four points verbal rating scale (VRS) in which 0 $=$ nil, $1=$ mild, $2=$ moderate, $3=$ severe. Patients grading for postoperative analgesia was recorded where 


required.

$0=$ nil, $1=$ mild, $2=$ moderate, $3=$ good, $4=$ excellent. Side effects were treated as

Data were statistically described in terms of mean \pm standard deviation $( \pm$ SD) or frequencies (number of cases) and relative frequencies (percentages) when appropriate. Comparison between the 2 studied groups was done using Student $t$ test for independent samples in comparing quantitative data. For comparing categorical data, Chi square $\left(\chi^{2}\right)$ test was performed. Yates correction was used in stead when the expected frequency is less than 5. A probability value ( $p$ value) less than 0.05 was considered statistically significant. All statistical calculations were done using computer programs Microsoft Excel version 7 (Microsoft Corporation, NY, USA) and SPSS (Statistical Package for the Social Science; SPSS Inc., Chicago, IL, USA) statistical program.

\section{Results}

Sixty consecutive patients completed the study. There were no demographic data and surgical time differences among both groups as regards to age $(31.4 \pm 7.7) \mathrm{yr},(29.8 \pm 6.5) \mathrm{yr}$, body weight $(66.7 \pm 8.6) \mathrm{kg},(68.6 \pm 7.8) \mathrm{kg}$, height $(163 \pm 8.8) \mathrm{cm},(162.3 \pm 7.6) \mathrm{cm}$ and duration of surgery $(61 \pm 23.4) \mathrm{min},(54 \pm 20.8) \mathrm{min}$ (Table 1). There were no differences among the two groups as regards intraoperative ( mean blood pressure, heart rate, oxygen saturation ) at any of the measured time.

In comparison with placebo, patients in the gabapentine group had significantly lower VAS scores in all time intervals $(1,3,6,12,18,24)$ hours postoperatively. ( $4.3 \pm 1.1,2.8 \pm 0.6$ ) , $(3.6 \pm 0.9,2.2 \pm 0.5),(3.2 \pm 0.8,2.1 \pm 0.6),(2.6 \pm 0.7,1.7 \pm 0.4),(2.2 \pm 0.5,1.1 \pm$ $0.8),(2.1 \pm 0.4,1.0 \pm 0.7)$ ( fig 1$),($ Table 2 )

The mean time to first analgesic administration was longer in the patients included in the gabapentine group. The total meperidine consumption after surgery in the first 24 hours in the gabapentine group was significantly less ( $48.8 \pm 9.7,93.8 \pm 8.4$ )

(Table 3 ). Patient satisfaction with their postoperative pain management( score $=3-4$ ) was significantly greater in the gabapentine group compared with placebo ( $26-20)$ patients respectively ( Table 3 ).

As regards side effects during the postoperative period we found the incidence of dizziness was insignificant between both groups ( 5 and 6 patients ) in placebo and gabapentine groups respectively. There is higher incidence of nausea, vomiting and the use of antiemetic medication in placebo group in comparison with gabapentine group

$(12,5),(8,3),(11,3)$ respectively (Table 4).

Table 1: Demographic data and operative duration

\begin{tabular}{llll}
\hline & $\begin{array}{l}\text { Gabapentine } \\
\mathrm{n}=30\end{array}$ & $\begin{array}{l}\text { Placebo } \\
\mathrm{n}=30\end{array}$ & $p$ value \\
\hline Age (years) & $31.4 \pm 7.7$ & $29.8 \pm 6.5$ & 0.787 \\
Gender (male/female) & $37 / 23$ & $33 / 27$ & 0.681 \\
Body weight (kg) & $66.7 \pm 8.6$ & $68.6 \pm 7.8$ & 0.707 \\
Height $(\mathrm{cm})$ & $163.2 \pm 8.8$ & $162.3 \pm 7.6$ & 0.763 \\
Duration of surgery (min) & $61 \pm 23.4$ & $54 \pm 20.8$ & 0.728 \\
\hline
\end{tabular}

Values are expressed as mean +/- SD or absolute number 
Table 2: Postoperative (VAS)

\begin{tabular}{llll}
\hline & $\begin{array}{l}\text { Gabapentine } \\
\mathrm{n}=30\end{array}$ & $\begin{array}{l}\text { Placebo } \\
\mathrm{n}=30\end{array}$ & $p$ value \\
\hline 1 hour & $4.3 \pm 1.1$ & $2.8 \pm 0.6$ & $<0.001$ \\
3 hours & $3.6 \pm 0.9$ & $2.2 \pm 0.5$ & $<0.001$ \\
6 hours & $3.2 \pm 0.8$ & $2.1 \pm 0.6$ & $<0.001$ \\
12 hours & $2.6 \pm 0.7$ & $1.7 \pm 0.4$ & $<0.001$ \\
18 hours & $2.2 \pm 0.5$ & $1.1 \pm 0.8$ & $<0.001$ \\
24 hours & $2.1 \pm 0.4$ & $1.0 \pm 0.7$ & $<0.001$ \\
\hline
\end{tabular}

Values are expressed as mean +/- $S D$

Table 3: Postoperative analgesia, meperidine requirement and related side effects

\begin{tabular}{|c|c|c|c|}
\hline & $\begin{array}{l}\text { Gabapentine } \\
\mathrm{n}=30\end{array}$ & $\begin{array}{l}\text { Placebo } \\
n=30\end{array}$ & $p$ value \\
\hline Time to $1^{\text {st }}$ meperidine injection ( $\mathrm{hr}$ ) & $6.6 \pm 4.2$ & $2.4 \pm 2.0$ & $<0.001$ \\
\hline Total meperidine consumption (mg) & $48.8 \pm 9.7$ & $93.8 \pm 8.4$ & $<0.001$ \\
\hline Worst pain score & $4.0 \pm 2.4$ & $6.0 \pm 1.4$ & $<0.001$ \\
\hline \multicolumn{4}{|l|}{ Meperidine related side effects } \\
\hline - Nausea & $5(16.67 \%)$ & $13(43.33 \%)$ & 0.049 \\
\hline - Satisfaction & $27(90.00 \%)$ & $19(63.33 \%)$ & 0.033 \\
\hline
\end{tabular}

Values are expressed as mean +/- SD or absolute number

Table 4: Side effects related to meperidine in both groups

\begin{tabular}{llll}
\hline & $\begin{array}{l}\text { Gabapentine } \\
\mathrm{n}=30\end{array}$ & $\begin{array}{l}\text { Placebo } \\
\mathrm{n}=30\end{array}$ & $p$ value \\
\hline Nausea & $3(10.00 \%)$ & $7(23.33 \%)$ & \\
$\quad$ - Mild & $2(6.67 \%)$ & $4(13.33 \%)$ & 0.642 \\
- Moderate & $0(0.00 \%)$ & $2(6.67 \%)$ & \\
- Severe & $2(6.67 \%)$ & $9(30.00 \%)$ & 0.045 \\
Vomiting & $3(10.00 \%)$ & $11(36.67 \%)$ & 0.033 \\
Use of anti emetics & $6(20.00 \%)$ & $5(16.67 \%)$ & 1.000 \\
Dizziness & & & \\
Sedation score: & $4(13.33 \%)$ & $3(10.00 \%)$ & \\
- Mild & $2(6.67 \%)$ & $1(3.33 \%)$ & 0.497 \\
- Moderate & $0(0.00 \%)$ & $1(3.33 \%)$ & \\
- Severe & $2(6.67 \%)$ & $1(3.33 \%)$ & 1.000 \\
Somnolence &
\end{tabular}

Values are expressed as absolute number and percentage. 
Figure 1: Post operative (VAS) between studied groups.

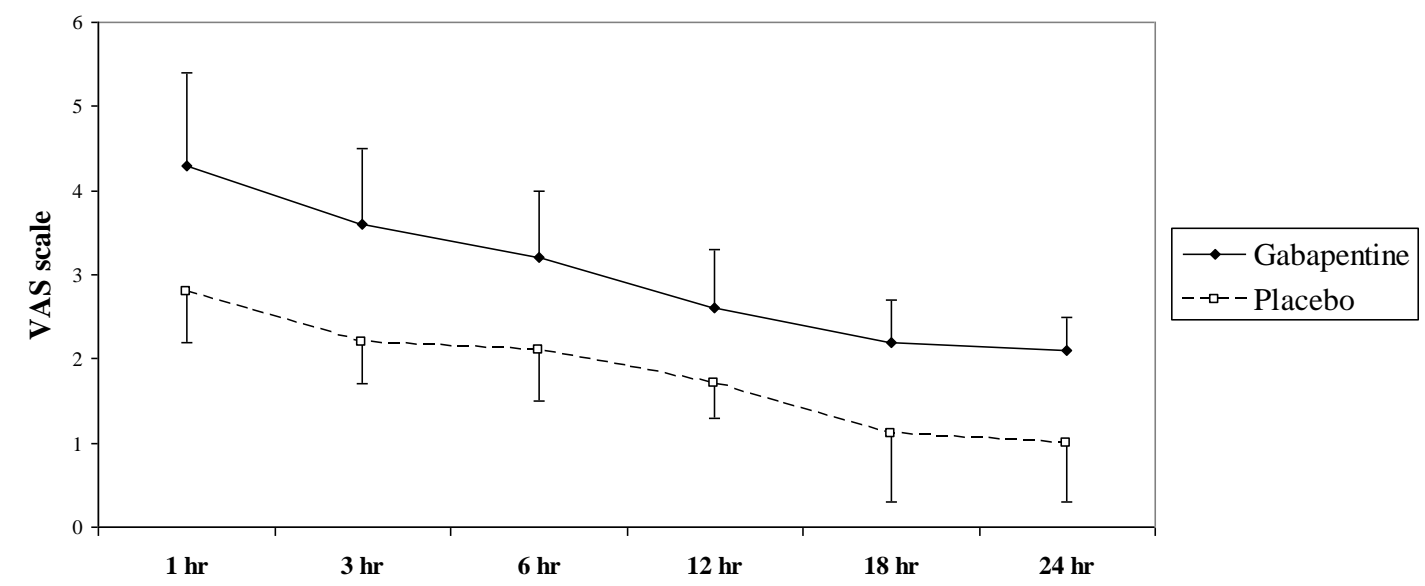

\section{Discussion}

The results of this study showed that a single oral dose of $1200 \mathrm{mg}$ gabapentine given two hours before tonsillectomy decreased post operative pain score, reduced the need of postoperative meperidine consumption during the first 24 hours postoperatively, and decreased meperidine related side effects compared with placebo.

The main aim of combining different analgesic drugs and techniques is to obtain synergistic or additive actions that allow a smaller dose of each agent to be used and thereby improve the safety profile. This can be achieved by combining analgesics acting at different locations.

Gabapentine reduced tactile allodynia ( which is $\alpha-$ amino - 3 hydroxyl - 4- isoxazolaproprionate AMPA ) after incision ${ }^{12}$ and reduced mechanical hyperalgesia ( which is N-methyl - D aspartate mediated NMDA ) in a rat model of postoperative pain $^{13}$. Mechanical hyperalgesia surrounding the wound postoperatively together with induced ,secondary hyperalgesia share a common mechanism, and central neuronal sensitization might contribute to some aspects of postoperative pain therefore, antihyperalgesic drugs such as gabapentine

The lower scores of postoperative nausea and vomiting in the gabapentine may have a role in postoperative pain control, and combination of antinociceptive

and antihyperalgesic drugs may provide synergistic effects ${ }^{14}$. Pretreatment with gabapentine also blocked the development of hyperalgesia, suggesting a preventive effect of gabapentine, and a selective effect on the nociceptive process involving central sensitization ${ }^{15}$.

Previous clinical studies with gabapentine for postoperative analgesia have shown promising results. Oral gabapentine $1200 \mathrm{mg}$ administered one hour before surgery decreased pain scores in the early postoperative period and postoperative morphine consumption in spinal surgery patients, while decreasing morphine-associated side effects ${ }^{16}$. Another study demonstrated that a single dose of 1200 gabapentine given 2 to 2.5 hour before induction of anesthesia reduced the need for additional postoperative pain treatment by $40 \%$ during the first 20 postoperative hours in patients undergoing vaginal hysterectomy ${ }^{17}$. Ganter et $a l^{18}$, used gabapentine for diffuse intractable pain following face lift surgery and reported dramatic improvement in postoperative pain. Also AL-Mujadi et $a l^{8}$, found preoperative gabapentine decreases pain scores and postoperative morphine consumption in patients following thyroid surgery.

group might be due to the diminished need for postoperative meperidine consumption 
and because of an antiemetic effect of gabapentine ${ }^{17}$. Our results supported by most recent meta-analysis done by using databases of 22 randomized, control trials by Tiippana et $a l^{19}$ who concluded that gabapentine is effective in reducing pain intensity, opioid consumption and opioid related adverse effects after surgery and concluded that gabapentine has very few adverse effects.

The dose we studied (1200 mg) is within the limits of a single dose in the treatment of neuropathic pain, as the recommended dose is 300 to $1200 \mathrm{mg}$ three times daily ${ }^{3}$. In previous studies the dose of gabapentine ranged from $300 \mathrm{mg}$ to 1200 $\mathrm{mg}$ preoperatively. The studies which evaluate the lowest doses yield the least impressive reduction in analgesic consumption $^{2,11,20}$. A review of 16 studies by Ho et al, demonstrated that a single preoperative dose of gabapentine ( $1200 \mathrm{mg}$ ) reduced pain intensity, opioid consumption and opioid related adverse effects for the first $24 \mathrm{~h}$ postoperatively ${ }^{21}$.

Gabapentine has been reported as an anxiolytic drug in previous studies ${ }^{22,23}$. Reducing preoperative anxiety with gabapentin may have contributed to the improved postoperative analgesia and to reduced meperidine requirement because there is possible association between preoperative anxiety and post operative pain $^{24}$.

Dizzeness and somnolence have been demonstrated to be the commonest side effects of gabapentine in previous controlled studies of chronic pain pa, $^{3,25,26,27}$. These studies however, were usually performed in patients with long term gabapentine use. In this study only one single oral dose $1200 \mathrm{mg}$ was used and there was no significance difference between both groups as regards side effects related to gabapentine ( dizzeness and somnolence ), non of the patients required treatment and the side effects were well tolerated. However, a meta-analysis done by Seib and $\mathrm{Paul}^{28}$, concluded that gabapentine given preoperatively decrease pain scores and analgesic consumption in the first 24 hours after surgery, but could not demonstrate a significant reduction in the incidence of side effects but this results needs further evaluation due to the small number of patients enrolled.

In conclusion gabapentine used preemptively decrease pain scores in post operative period of tonsillectomy and decrease postoperative meperidine consumption and meperidine related side effects. Gabapentine could be a useful adjunctive for pain management postoperatively.

\section{References}

(1) Nikanne E, Virtmaniemi J, Aho M, Kokki H.( 2003): ketoprofen for post operative pain after uvulopalatopharyngoplasty and tonsillectomy: two week follow up study. Otolaryngol Head Neck Surg; 129(5):577-81.

(2) Goa kl, Sorkin EM. (1993): Gabapentine: Areview of its pharmacological properties and clinical potentials in epilepsy. Drugs ; 46: 409 27.

(3) Eckbardt K, Ammon S , Hofmann,U, Riebe A ,Gugeler N , Mikns G. (2000): Gabapentine enhances the analgesic effect of morphine in healthy volunteers. Anesthesia Analgesia; 91: $185-91$

(4) Shimoyama M, Shimoyana N, Inturrissi CE ,Elliott KJ. (1997):Gabapentine enhances the antinociceptive effects of spinal morphine in the rat tail- flick test. Pain ; $72: 375-82$.

(5) Iou ZD ,CalcuttNA, Higuera ES, et al.(2002): Injury type -specific calcium channel alpha 2 delta -1 subunit up-regulation in rat neuropathic pain models correlates with antiallodynic effects of gabapentine. J Pharmacol Exp The; 303:1199-205.

(6) Dirks J, Fredensborg BB, Cbristensen D, Fomsgaard JS, Flyger H, Dabi JB. (2002):

A randomized study of the effects of single dose gabapentin versus placebo on postoperative pain and morphine consumption after mastectomy.Anesthesiology ; 97:560-4.

(7) Fassoulaki A, Patris K, Sarantopoulos C, Hagan Q. (2002):The analgesic effects of 
gabapentin and mexiletine after breast surgery for cancer. Anesth Analgesia; 95:985-91.

(8) Pandey CK, Sabay S, Gupata D,et al.(2004):

Preemptive gabapentin decrease postoperative pain after lumber discoidectomy. Can J Anesthesia ; 51: 986-9.

(9) AL-Mujadi H, A-Refai AR, Katzarov MG ,et al.(2006):Preemptive gabapentine reduces postoperative pain and opioid demand following thyroid surgery. Can J Anesth; $53: 268-73$.

(10) Pandey CK , Singhal V , K umar M, et al.(2005):Gabapentine provides effective postoperative analgesia whether administered pre- emptively or post - incision. Can J Anesth ; 52 : $827-31$.

(11) Backonja M, Beydoun A, Edwards KR, Schwartz SL, Fonseca V, Hes M, Lamoreuaux L, Garofalo E. (1998): Gabapentin For The Symptomatic Treatment of Painful neuropathy In Patients With Diabetes Mellitus: A randomized controlled trial. JAMA ; 280:1831-6.

(12) Rowbotham M, Harden N, Stacey B, Bernstein P, Magnus-Miller L. (1998):

Gabapentin for the treatment of postherpetic neuralgia; A randomized controlled trial. JAMA ; 280 :1837-42.

(13) Cheong JK, Pan HL, Eisenach JC. (2000): Antiallodynic effect of intrathecal gabapentin and its interaction with clonidine in a rat model of postoperative pain. Anesthesiology; 92:112631 .

(14) Field MJ, Holloman EF, Mccleary S, Hughes J, Singh L. (1997): Gapapentin and s-(+)-3-isobutylgaba in a rat model of postoperative pain.J pharmacola Exp Ther; 282:1242-6.

(15) Dirks J, Moinich S , Hilsted KL, Dahl JB.(2002): Mechanism of Postoperative

Pain: Clinical Indication for a contribution of central neuronal sensitization Anesthesiology; 97:1591-6.

(16) Mao J, Chen LL.(2000): Gabapentin in pain management. Anesth Analg; 9: 680-7.

(17 ) Turan A, Karamanlioglu B, Memis D, et al.(2004): Analgesic effects of gabapentin after spinal surgery. Anesthesiology; 100:935-8.

(18) Rorarius MG, Mennander S, Suminen P, et al.(2004): Gabapentin for the prevention of postoperative pain after vaginal hysterectomy. Pain; 110:175-81.

(19) Ganter .H.I ,Yilmaz B , Gurunluogly R , Algan H.(2006): Use of gabapentine, neurontin ,for relief of intractable pain developed after face - lift surgery Anesth Plast Surg; 30 (6) $709-11$.

(20) Tiippana E .M , Hamunen K , Kontinen V.K , Eija K.(2007): Do surgical patients benefit from perioperative gabapentin / pregabalin ? a systematic review of efficacy and safety. Anesth Analg; 104 : 1545 - 56 .

(21) Pandy CK, Priye S, Singh S, Singh U, Singh RB, Singh PK.(2004) Preemptive use of gabapentine significantly decreases postoperative pain and rescue analgesic requirements in laparoscopic cholecystectomy.

Can J Anesth;51:358- 63.

(22) Ho KY, Gan TJ, Habib AS.(2006): Gabapentin and postoperative pain - a systematic review of randomized controlled trials. Pain; $126: 91-101$.

(23) Pollack MH, Mattbews J, Scott EL. (1998): Gabapentin as a potential treatment anxiety disorders. AM J Psychiatry; 992-3.

(24) Cbouinard G, Beauchair L , Belanger MC.(1998): Gabapentin long -term antianxiety and hypnotic effects in psychiatric patients with comorbid anxiety- related disorders. Can J Psychiatry; 43:305.

(25) Gilon I, Biederman J, Jbamands K, Hong M. (2003): Gabapentin blocks and revers antinociceptive morphine tolerance in the rat paw-pressure and tail -flick tests nesthesiology; 98:1288-92.

(26) Rice AS , Maton s.(2001): Gabapentin in postherpetic neuralgia ; a randomized double blind, placebo controlled study. Pain, 94; 215 24.

(27) Mclean MJ, Morrell MJ, Willmore $\mathrm{lj}$, Privitera MD, Faught RE, Holmes Magnus Miller L, Bernstein P, Rose-legatt. (1999): Safety and tolerability of gabapentin as adjunctive therapy in a large, multicenter study. Epilepsia,40; 965-71.

(28) Seib R, Paul J.(2006): Preoperative gabapentine for postoperative analgesia ; a meta -analysis. Can J Anesth ; $53: 461-69$. 



\title{
تأثير عقار الجابابنتين كمسكن للألم فى حالات استئصسال اللوزتين
}

\author{
د. وليد عبد المجيد - د. صلاح عبد الرازق - د. أحمد محمد نصار

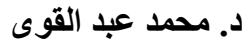

الغرض من الدراسة

أجريت هذه الدراسة لتقيم الثاثير الوقائى للجابابنتين لتسكين الألأم بعد عملية استئصسال اللوزتين وكذللك تأثيره

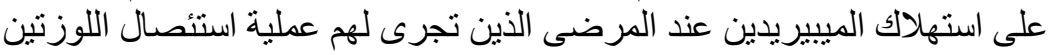

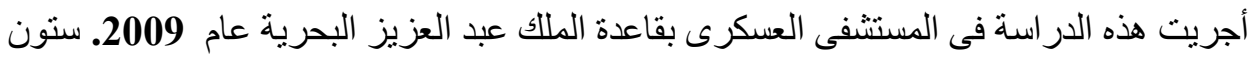

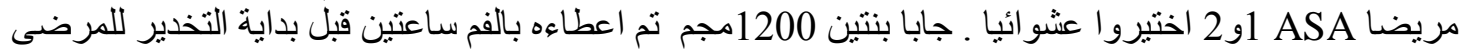
الذين ستجرى لهم عملية استئصال اللوزنين بتخدير كلى. ومن ثم تم تسجيل الألأم بعد العملية خلال 24,18,12,6,3,1

و أيضا تم اعطاء المرضى ميبيردين 1مجم / كجم بالعضل كل 4 ساعات وذللك لو كان معدل الألم أكثر من أو أو الكرئ يساوى 3 أو اذا طلبه المريض 0 وتم تدوين الجرعة الكليه المعطاه للمريض باعل

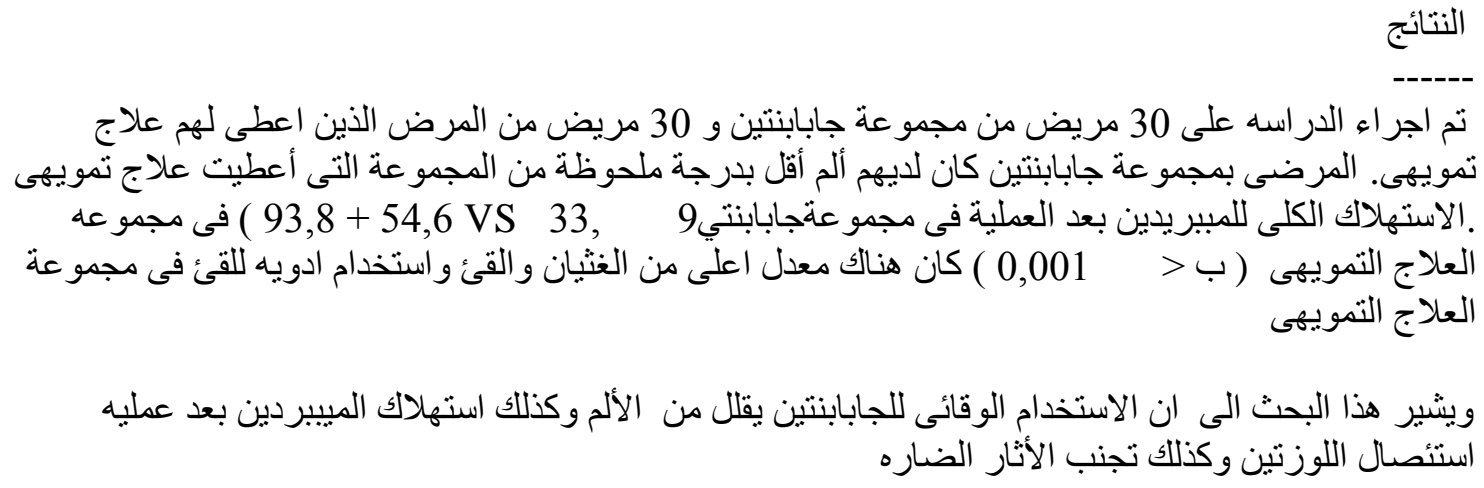

